\title{
Variability in snow layering and snow chemistry in the vicinity of two drill sites in western Dronning Maud Land, Antarctica
}

\author{
Malin Stenberg, ${ }^{1}$ Margareta Hansson, ${ }^{2}$ Per Holmlund, ${ }^{1}$ Lars Karlöf ${ }^{3}$ \\ ${ }^{1}$ Department of Physical Geography, Stockholm University, S-106 91 Stockholm, Sweden \\ ${ }^{2}$ Department of Meteorology, Stockholm University, S-106 91 Stockholm, Sweden \\ ${ }^{3}$ Norwegian Polar Institute, N-9006 Tromsø, Norway
}

\begin{abstract}
As part of the pre-site survey in Dronning Maud Land for the European Project for Ice Coring in Antarctica (EPICA), the spatial variability of snow-layer thickness and snow chemistry was studied at two geographically different ice-core drill sites. The study aimed to quantify error bars on accumulation rates derived from firn and ice cores. One site is located on the polar plateau at Amundsenisen $\left(76^{\circ} \mathrm{S}, 8^{\circ} \mathrm{W}\right)$ and the other in the coastal area at Maudheimvidda $\left(73^{\circ} \mathrm{S}, 13^{\circ} \mathrm{W}\right)$. Medium-deep ice cores $(100 \mathrm{~m})$ and shallow firn cores $(10-20 \mathrm{~m})$ were drilled and snow pits $(0.5-2.5 \mathrm{~m})$ were dug at each site. At Amundsenisen a large $(16 \mathrm{~m} \times 6 \mathrm{~m} \times 2.5 \mathrm{~m}$ deep $)$ snow pit was dug. Snow structure in this large snow pit was mapped using optical surveying equipment, and photographically documented. Samples for analysis of nine ions and oxygen isotopes were collected along one depth profile. Density and in situ electrical conductivity measurements were made along three depth profiles. Snow-layer variability was studied in two different areas and at two different scales. At a regional scale, measured by snow-radar soundings, the variability was $8 \%$ on the polar plateau and $45 \%$ in the coastal area. The variability at a micro-scale in the large snow pit was $9 \%$. The results indicate that ice cores from the polar plateau are more representative for a larger area than ice cores drilled in the coastal area. There is no doubt that there are significant error bars on highresolution accumulation data received from firn and ice cores, especially from the coastal area, but averaging over tens of years reduces the error in accumulation estimates.
\end{abstract}

\section{INTRODUGTION}

The frozen archive of snow and ice accessed by coring in the polar regions is an invaluable source of information about climate and environmental history. However, the question arises how representative the information from ice cores is at a regional scale. Post-depositional processes such as redistribution of snow by the wind may influence both the snow-layer thickness and the chemical signal in the snow. In the area around two medium-deep ice-core drill sites the snow-layer thickness and snow chemistry have been analyzed in detail in order to study the spatial variability. One drill site, Camp Victoria, is located at Amundsenisen at $76^{\circ} 00^{\prime} 01^{\prime \prime} \mathrm{S}$, $8^{\circ} 03^{\prime} 03^{\prime \prime} \mathrm{W}$, approximately $550 \mathrm{~km}$ from the coast, at $2400 \mathrm{~m}$ a.s.l. (Fig. 1). The other drill site, Camp Maudheimvidda, is located at $73^{\circ} 06^{\prime} 19^{\prime \prime} \mathrm{S}, 13^{\circ} 09^{\prime} 54^{\prime \prime} \mathrm{W}$, approximately $10 \mathrm{~km}$ from the Swedish station Wasa and some $140 \mathrm{~km}$ from the coast, at $360 \mathrm{~m}$ a.s.l. (Fig. 1). The drilling, carried out using logistics provided by the Swedish Antarctic Research Programme (SWEDARP 1997/98), was a collaborative Scandinavian/ Dutch effort as a pre-site survey for the European Project for Ice Coring in Antarctica (EPICA).

This study focused on an attempt to detect irregularities in snow layering, and attention was therefore paid to pit analyses and detailed snow-radar soundings. Similar snow-pit studies have been performed over several decades in eastern Dronning Maud Land in the area around the two Japanese stations Syowa and Mizuho (NIPR, 1997). The aim of this paper is to highlight the relatively high rates of variability in snow layering at both coastal and inland Antarctic sites which impact on detailed analyses of firn and ice cores.

\section{METHODS AND ANALYSES}

One medium-deep ice core (133 m) was drilled at Camp Victoria, and two medium-deep ice cores (104 and $103 \mathrm{~m}$ ) at Camp Maudheimvidda. At each site, shallow firn cores (10$20 \mathrm{~m})$ were drilled and snow pits $(0.5-2.5 \mathrm{~m})$ were dug. The area around Camp Maudheimvidda and the route up to Camp Victoria were also investigated with detailed snowradar soundings. Technical information about the drilling and snow-radar soundings is provided in the report from the SWEDARP 1997/98 expedition (Holmlund and others, 1999).

At Camp Victoria a large snow pit was dug about $50 \mathrm{~m}$ from the drill site. The pit, excavated by a vehicle, was $2.5 \mathrm{~m}$ deep and $16 \mathrm{~m}$ long in one direction, with a $6 \mathrm{~m}$ long perpendicular trench through the centre. Structures were mapped using optical surveying equipment and photographically documented (Fig. 2). Samples for chemical analyses (nine ions and oxygen isotopes) were collected at depth intervals of $4 \mathrm{~cm}$ along one profile (Y6). The sampling was done under cleanroom conditions (Stenberg and others, 1998) with tools made of polyethylene. Double samples and blanks were collected in order to check any possible contamination. The snow samples were transported in a freezer at $-20^{\circ} \mathrm{C}$ and melted immediately before the simultaneous analysis of $\mathrm{Na}^{+}, \mathrm{NH}_{4}^{+}, \mathrm{K}^{+}$, 


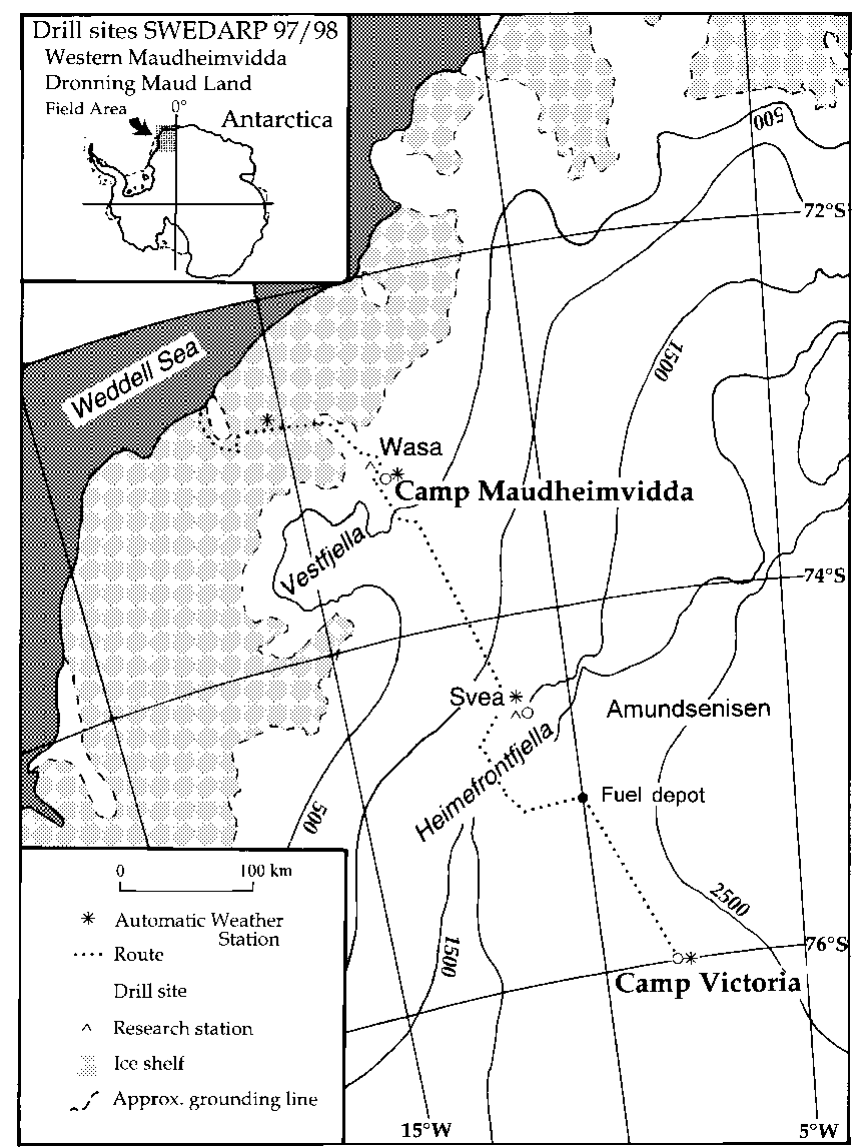

Fig. 1. Location map. The traverse route and the two drilling sites are marked.

$\mathrm{Mg}^{2+}, \mathrm{Ca}^{2+}, \mathrm{Cl}^{-}, \mathrm{NO}_{3}{ }^{-}, \mathrm{SO}_{4}{ }^{2-}$ and $\mathrm{CH}_{3} \mathrm{SO}_{3}{ }^{-}$on a Dionex ion-chromatography system at the Department of Meteorology, Stockholm University. The samples were refrozen and transported to the Department of Geophysics, Copenhagen University, Denmark, for oxygen-isotope $\left(\delta^{18} \mathrm{O}\right)$ analyses.

Density and electrical conductivity measurements (ECMs; Hammer, 1980) were made along three different

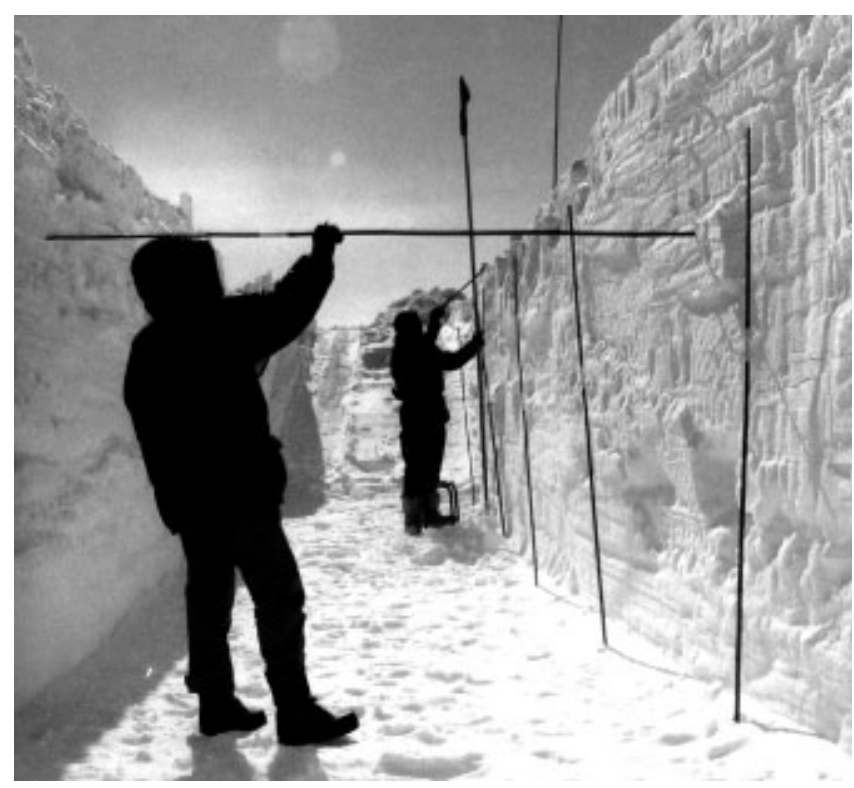

Fig. 2. Mapping of snow layers in a snow pit at Camp Victoria, Amundsenisen.

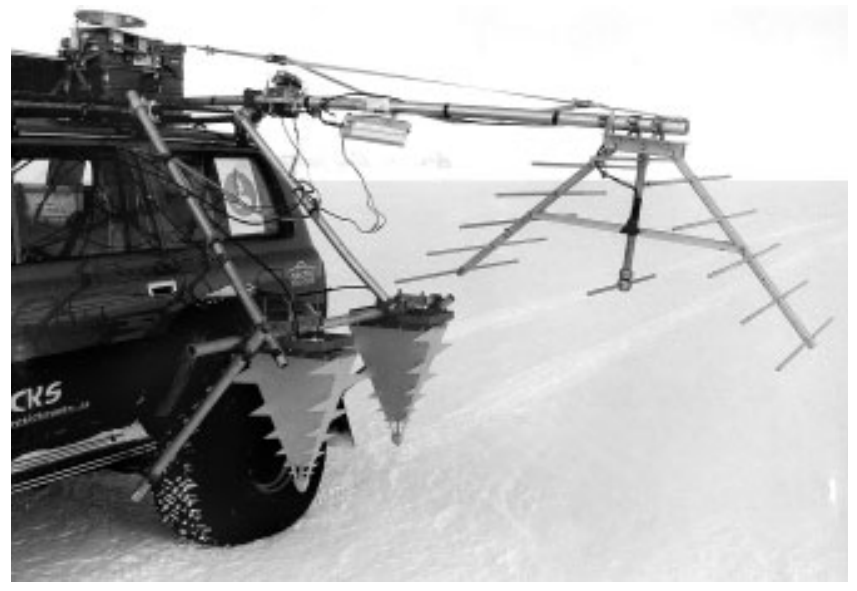

Fig. 3. Antennae configuration on the Toyota Landcruiser for geophysical surveys. The antennas to the right were used for depth soundings (150-160 MHz) and the two close to the vehicle were used for snow radar studies $(500-2500 \mathrm{MHz})$.

profiles (Y6, X6 and X12) on the pit walls. The ECMs were made in situ directly on the snow-pit wall: a test since this is an unusual way of using the EGM equipment. The electrodes were dragged manually at a constant speed along the wall. The uncertainty in the depth scale is estimated to be $\pm 10 \mathrm{~cm}$ since no depth-counter was connected to the ECM instrument. The ECM profile was always reproduced in a second run at each profile which gave confidence in this method of using the EGM as a mapping tool.

Snow layering was also investigated with a high-resolution radar system based on a Hewlett-Packard Network Analyzer $(8753 \mathrm{~B}$ and $\mathrm{D})$. This is a continuous-wave step frequency radar, transmitting 201 evenly distributed frequencies. In these studies three different bandwidths were used: $1.5 \mathrm{GHz}$ centred around $1.5 \mathrm{GHz}$ penetrating $15 \mathrm{~m}$ of firn; $250 \mathrm{MHz}$ centred around $900 \mathrm{MHz}$ penetrating about $100 \mathrm{~m}$; and $6 \mathrm{MHz}$ centred around $160 \mathrm{MHz}$ penetrating about $3000 \mathrm{~m}$. Microwave measurements were performed using an output power of 1-4 W, while very high-frequency measurements were carried out using an output power of about $100 \mathrm{~W}$. The radar was placed in a Toyota Landcruiser with antennas and amplifiers mounted on metal frames outside the vehicle (Fig. 3) and operated by using a notebook computer from the front seat of the vehicle. Kinematic global positioning system (GPS) measurements were made along the radar profiles.

The snow-layer variability was analyzed in two different ways: by optical surveying of snow layers in the snow pit at a micro-scale, and by snow-radar soundings at a regional scale. Two of the most complete snow layers that were easy to follow on the snow-pit walls were chosen for calculations of the standard deviation of layer thickness: one layer close to the snow surface (about $50 \mathrm{~cm}$ depth), and the other close to the bottom of the snow pit (about $220 \mathrm{~cm}$ depth) (Fig. 4). Readings of the distance between the snow surface and the snow layer were made at $10 \mathrm{~cm}$ intervals along the 6 and the $16 \mathrm{~m}$ long walls. In the vicinity of the Camp Victoria drill site, a $12 \mathrm{~km}$ long snow-radar profile was selected. A welldefined snow layer at a relative depth of about $17 \mathrm{~m}$ was digitised and the snow-layer thickness was measured. The same procedure was used for a snow-radar profile from Maudheimvidda that started at Fossilryggen and extended $42 \mathrm{~km}$ towards the coast. From this profile a well-defined snow layer at a relative depth of about $15 \mathrm{~m}$ was selected. 

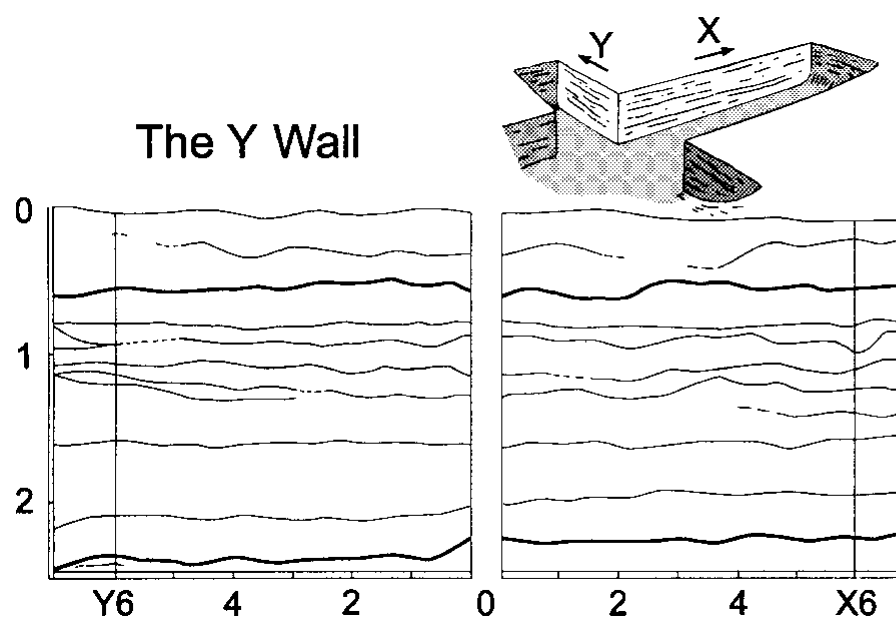

\section{The X Wall}

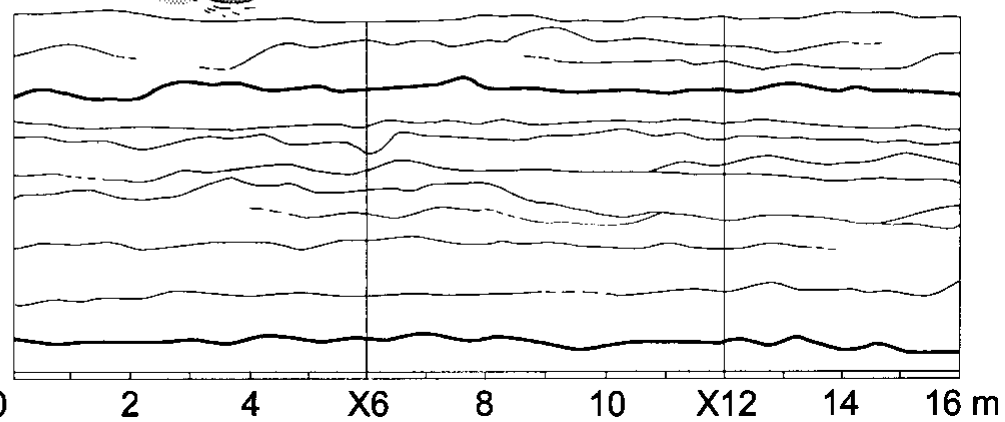

Fig. 4. Ice layers and crusts in the snow pit at Camp Victoria. The two layers marked with thicker lines were selected for the calculation of the standard deviation of snow-layer variability. Sampling and measuring positions are marked as $\mathrm{Y} 6$, X6 and $X 12$. ECMs and density measurements were made at each of these profiles, and snow for chemical analyses (ions and $\delta^{18} O$ ) was sampled at $\mathrm{Y} G$.

\section{RESULTS AND DISGUSSION}

In the large snow pit at Camp Victoria it was possible to visualise snow-layer variability on a micro-scale. Thin $(1-$ $3 \mathrm{~mm}$ ) ice lenses or crust layers, indicated by lines in Figure 4, marked boundaries between snow layers. The standard deviation of snow-layer thickness at a measurement spacing of $10 \mathrm{~cm}$ was $4.4 \mathrm{~cm}$ for the uppermost snow layer (about $50 \mathrm{~cm}$ depth) on the $16 \mathrm{~m}$ long wall and $3.9 \mathrm{~cm}$ for the lower snow layer (about $220 \mathrm{~cm}$ depth) at the same wall. For the
$6 \mathrm{~m}$ long wall the standard deviation of snow-layer thickness was $3.3 \mathrm{~cm}$ for the uppermost snow layer and $3.9 \mathrm{~cm}$ for the lower snow layer. This gives an average variability in snowlayer thickness of $9 \%$ at a micro-scale.

The standard deviation was also calculated from snowradar profiles from two sites using a linear interpolation interval of $50 \mathrm{~m}$ (Richardson and Holmlund, 1999). For the $12 \mathrm{~km}$ long snow layer on the polar plateau at a relative depth of about $17 \mathrm{~m}$ the standard deviation was $1.3 \mathrm{~m}$, and for the $42 \mathrm{~km}$ long coastal snow layer at a relative depth of
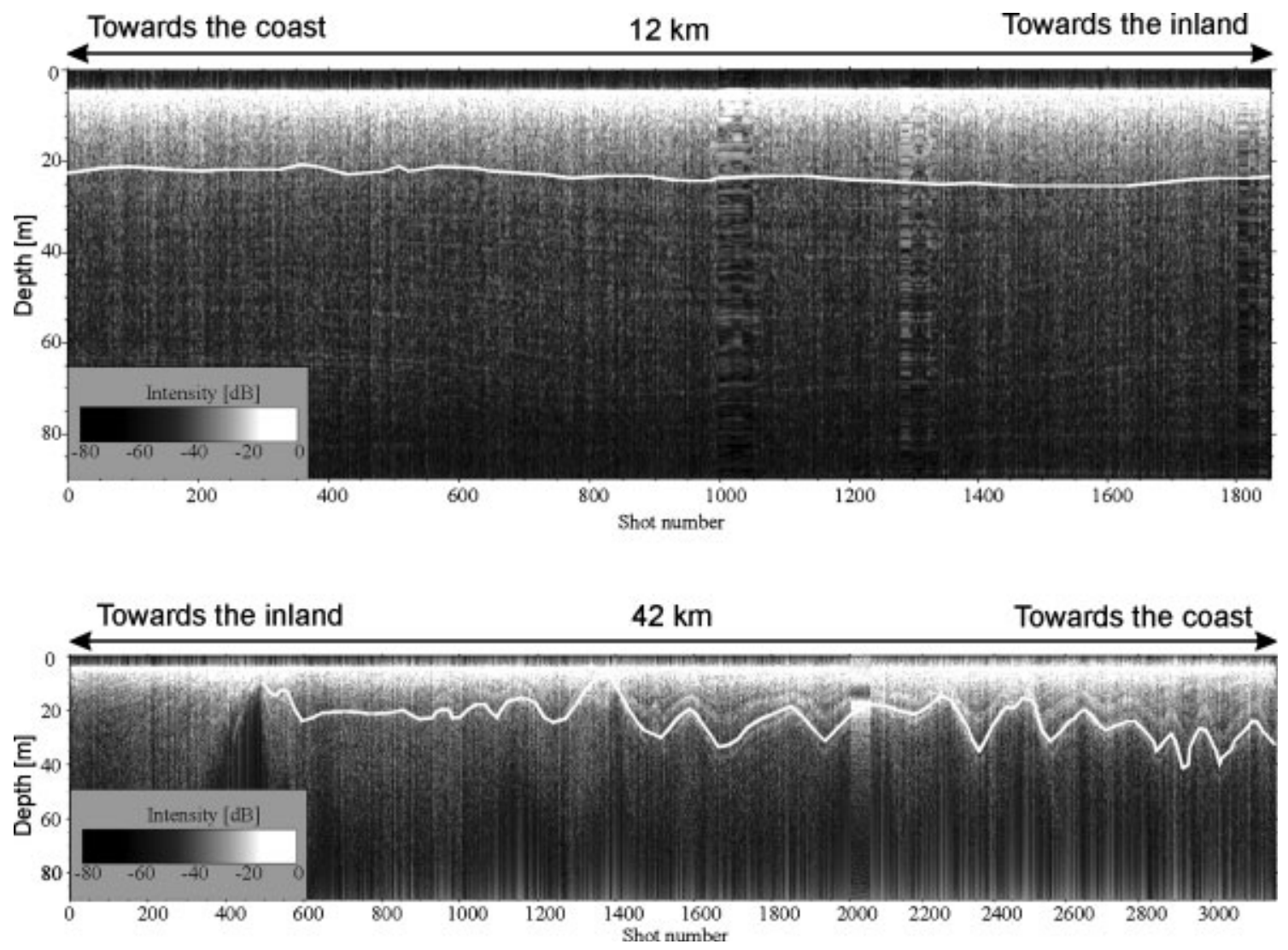

Fig. 5. Two snow-radar recordings selected for calculation of the standard deviation. The uppermost profile is from Amundsenisen where a snow layer at a relative depth of $17 \mathrm{~m}$ (the snow surface starts at $5 \mathrm{~m}$ ) was followed over $12 \mathrm{~km}$. The other layer, at an average relative depth of $15 \mathrm{~m}$, is from Maudheimvidda and was followed over $42 \mathrm{~km}$. 

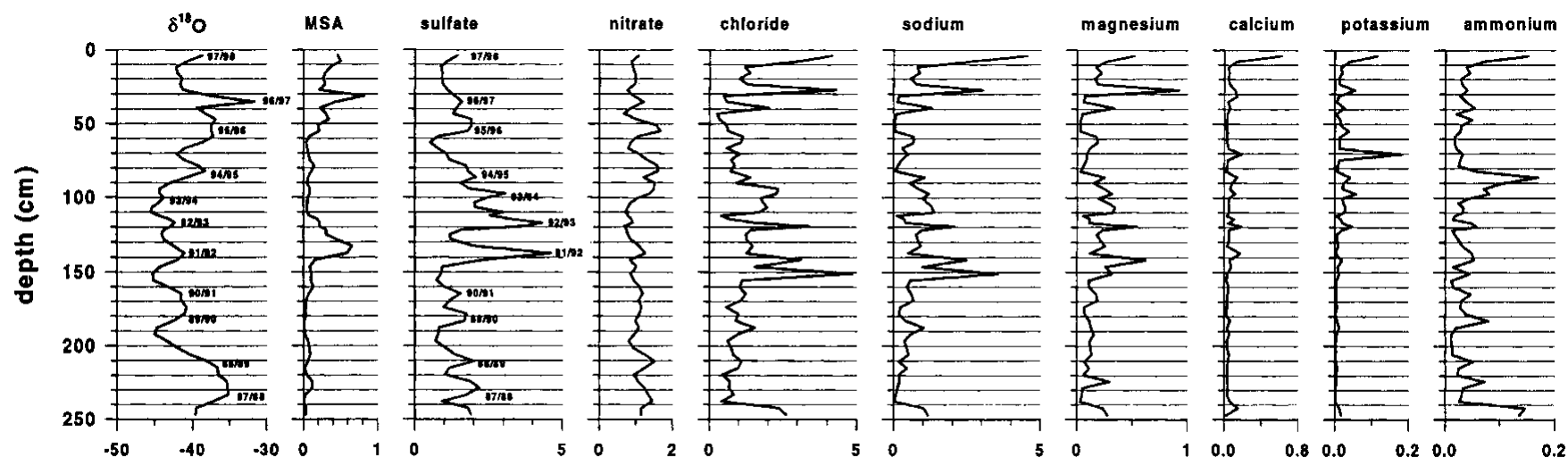

concentration $(\mu e q L-1)$

Fig. 6. Records of oxygen isotopes (per mil) and all ions $\left(\mu e q L^{-1}\right)$ from the profile sampled on the snow-pit wall at Y6. The records of oxygen isotopes and sulphate were used for dating.

about $15 \mathrm{~m}$ it was $6.8 \mathrm{~m}$ (Fig. 5). This gives a variability in snow-layer thickness at a regional scale of $8 \%$ on the polar plateau and $45 \%$ in the coastal area.

In radar recordings snow layers can easily be traced and followed along profiles. Convex areas of the surface are associated with wind abrasion and thus sastrugi. Such areas can easily be detected on radar recordings, as the layering record vanishes when approaching such an area and then reappears on the opposite side of the bulge. Such features can be traced at depth in two dimensions if there is a significant horizontal movement in the ice (Holmlund and Richardson, 1994; Richardson and others, 1997).

In association with the 1997-98 pre-site survey for the coming EPICA deep drillings, careful mapping was executed, especially at the Maudheimvidda drill site (Holmlund and others, 1999). Subglacial bedrock obstacles are mirrored at the ice surface, and due to wind drift of snow they are also mirrored in the accumulation pattern. On the polar plateau, however, the influence of the bedrock on the ice surface is much less prominent, and variations in the pathways of katabatic winds are believed to be the general cause for irregularities in snow layering (Richardson and Holmlund, 1999).

The depth profiles of nine ions and $\delta^{18} \mathrm{O}$ from the $\mathrm{Y} 6$ profile in the large snow pit are shown in Figure 6. A clear seasonal variability is found in ion concentrations and $\delta^{18} \mathrm{O}$ which suggests a preserved deposition record relatively undisturbed by wind redistribution. The seasonal signal is most distinct in the sulphate record. Assuming that each prominent sulphate peak indicates a summer, a preliminary dating was performed as indicated in Figure 6. This dating is supported by the nitrate record as well. An independent preliminary dating was performed based on the variations in the $\delta^{18} \mathrm{O}$ record, also indicated in Figure 6, which is in agreement with the dating based on the sulphate record. By counting the suggested years, the snow in the bottom of the $2.5 \mathrm{~m}$ deep snow pit is found to have been deposited in summer $1987-88$. The dating by seasonal variability in the chemistry at this site and for this period of time gives an approximate accumulation rate of $7.5 \mathrm{~cm}$ w.e. $\mathrm{a}^{-1}$.

At about $120-140 \mathrm{~cm}$ depth there are two prominent peaks in the sulphate record corresponding to the summers of 1991-92 and 1992-93. The first peak corresponds to a peak in $\mathrm{CH}_{3} \mathrm{SO}_{3}{ }^{-}$(methanesulphonate (MSA)), which indicates a substantial marine biogenic contribution. During summer 1992-93 there are slightly increased levels of MSA, but also higher levels of sea salt $\left(\mathrm{Na}^{+}, \mathrm{Cl}^{-}, \mathrm{Mg}^{2+}, \mathrm{Ca}^{2+}\right)$. Two volcanoes erupted during summer 1991, Mount Pinatubo, Philippines, in June and Cerro Hudson, Chile, in August. Large amounts of volcanic gases were injected into the stratosphere and reached Antarctica in 1992. They are likely to have contributed to the enlarged concentrations in the sulphate record during this period of time.

ECMs were made along three profiles at different sites on the walls of the Camp Victoria snow pit, together with density measurements (Fig. 7). Double measurements showed that the signal was reproducible, but there was a lag in the depth scale due to difficulties in measuring manually at a constant speed. No prominent features correspond-

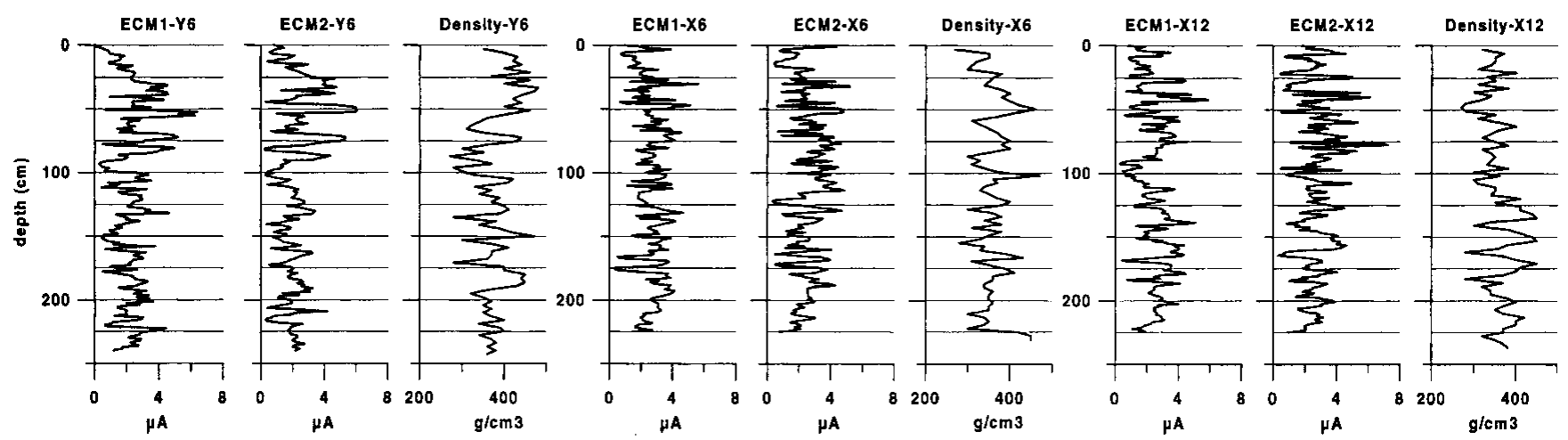

Fig. 7. The results from ECMs made in situ on the snow-pitwalls along profiles $16, X 6$ and X12, plotted together with the density. Double ECMs were made at each profile. 
ing to the peaks in the sulphate record were found in the ECM profiles. In situ ECM is not a well-established method and therefore not a reliable means of judging whether the sulphate peaks are of volcanic origin. There is a connection between the ECM and the density for each single profile, but no clear correlation between the different profiles was found, either in ECM or in density.

\section{CONGLUDING REMARKS}

The sites studied in this project show significant variability in snow layering over short distances. Pseudo-variations in accumulation rates will inevitably be incorporated in icecore interpretations. Adding the results from this study to data sampled on larger geographical areas (Richardson and Holmlund, 1999) highlights this important problem. For the sites used in this study the variability in snow layering was significantly larger in the coastal zone than in the polar plateau. The variability of snow-layer thickness at the regional scale was only $8 \%$ on the polar plateau and $45 \%$ in the coastal area. The variability of snow-layer thickness at the micro-scale in the $16 \mathrm{~m} \times 6 \mathrm{~m}$ snow pit at Camp Victoria on the polar plateau was on average $9 \%$, which is comparable to the variability at the regional scale on this site. Detailed chemical measurements along one profile in the $16 \mathrm{~m} \times 6 \mathrm{~m}$ snow pit showed clear seasonal signals in ion concentrations and oxygen isotopes, indicating that the deposition record is preserved and not heavily disturbed by redistribution of the snow by the wind. However, the ECM and density records from three different profiles in the same snow pit showed no clear correlation, indicating the problem of using a common depth scale for nearby measurements. This also applies at a micro-scale.

The radar soundings show irregularities in snow layering, and the rate of scattering may describe the environment in which the snow was once deposited. These observations show that there are significant error bars on high-resolution accumulation data received from firn and ice cores, especially from the coastal area, but averaging over tens of years reduces the error in accumulation estimates.

\section{AGKNOWLEDGEMENTS}

This work is a contribution to the "European Project for Ice Coring in Antarctica" (EPICA), a joint European Science
Foundation/European Commission (EG) scientific programme, funded by the EC under Environment and Climate Programme (1994-98) contract ENV4-CT95-0074 and by national contributions from Belgium, Denmark, France, Germany, Italy, The Netherlands, Norway, Sweden, Switzerland and the U.K. We thank the Swedish Polar Research Secretariat for logistic support. We thank the other participants in the field for their help with drilling, sampling and field measurements, and the construction of snow pits and the ice laboratory. K. Gjerde provided the GPS measurements. N. Gundestrup at the Department of Geophysics, University of Copenhagen, kindly performed the analyses of stable-oxygen isotopes. C. Richardson and R. Pettersson at Stockholm University provided the snow-radar data, and R. Pettersson also supported processing of the digital figures. M. Nyman did the drawings of snow layers in the large snow pit. Financial support came from the Swedish Natural Science Research Council, Stockholm University, and grants from Lillemor och Hans W:son Ahlmanns fond för geografisk forskning. Technical equipment was kindly lent to us from Hewlett-Packard $\mathrm{AB}$ and Geotronics AB.

\section{REFERENGES}

Hammer, G. U. 1980. Acidity of polar ice cores in relation to absolute dating, past volcanism, and radio-echoes. F. Glaciol., 25(93), 359-372.

Holmlund, P. and C. Richardson. 1994. A snow radar measurement of the accumulation gradient from the coast to $3000 \mathrm{~m}$ elevation, Dronning Maud Land. In Oerter, H., comp. Filchner-Ronne Ice Shelf Programme (FRISP). Report No. 8 (1994). Bremerhaven, Alfred Wegener Institute for Polar and Marine Research, 29-35.

Holmlund, P., M. Stenberg, L. Karlöf, M. Nyman, K. Gjerde and M. Thomassen. 1999. Glaciological studies in East Antarctica. In Grönlund, E., ed. Cruise report from SWEDARP 1997/98. Stockholm, Svenska Polarforskningssekretariatet, 37-45.

National Institute of Polar Research (NIPR). 1997. Antarctica: east Queen Maud Land/Enderby Land glaciological folio. Tokyo, National Institute of Polar Research.

Richardson, C. and P. Holmlund. 1999. Regional and local variability in shallow snow-layer depths from a $500 \mathrm{~km}$ continuous radar traverse on the polar plateau, central Dronning Maud Land, East Antarctica. Ann. Glaciol., 29 (see paper in this volume).

Richardson, C., E. Aarholt, S.-E. Hamran, P. Holmlund and E. Isaksson. 1997. Spatial distribution of snow in western Dronning Maud Land, East Antarctica, mapped by a ground-based snow radar. 7. Geophys. Res., 102(B9), 20,343-20,353.

Stenberg, M. and 7 others. 1998. Spatial variability of snow chemistry in western Dronning Maud Land, Antarctica. Ann. Glaciol., 27, 378-384. 